\title{
Contribuições da Educação Ambiental para o Turismo Sustentável na APA do Maracanã, São Luís (Maranhão, Brasil)
}

\section{Environmental Education Contributions for Sustainable Tourism in the Environmental Protection Area (APA) in Maracanã, São Luís (Maranhão, Brazil)}

\author{
Saulo Ribeiro dos Santos (SANTOS, S. R.) ${ }^{*}$ e \\ Protásio Cezar dos Santos (SANTOS, P. C.) ${ }^{* *}$
}

\begin{abstract}
RESUMO - A educação ambiental é uma forma de consolidação para uma consciência ecológica e uma prática efetiva do turismo sustentável em áreas de proteção ambiental. Portanto, objetiva-se neste artigo analisar como a educação ambiental junto à comunidade pode contribuir para o desenvolvimento de uma prática do turismo sustentável na Área de Proteção Ambiental do Maracanã em São Luís (Maranhão, Brasil). A metodologia é respaldada por pesquisa bibliográfica, documental e empírica, com análise quantitativa e qualitativa. Os resultados apontaram para a importância da educação ambiental em unidades de conservação, pois a partir de ações como estas se tem a construção de uma conduta na sociedade em relação aos recursos naturais, o que contribui para o desenvolvimento do turismo sustentável. Concluise que o turismo sustentável em áreas de proteção pode ser um auxiliador no processo de desenvolvimento equilibrado, a partir de práticas educacionais de cunho ambiental, social e cultural.
\end{abstract}

Palavras-chave: Educação ambiental; Turismo sustentável; Área de proteção ambiental do Maracanã.

\begin{abstract}
Environmental education is a form of consolidation for an ecological awareness and an effective practice of sustainable tourism in protected areas. Therefore, this article aims to analyze how the environmental education in the community can contribute to the development of a practice of sustainable tourism in the Environmental Protection Area (APA) in Maracanã, São Luís (Maranhão, Brazil). The methodology is supported by bibliographical, documental and empirical research, with quantitative and qualitative analysis. The results pointed to the importance of the environmental education in protected areas, because from some actions like those, the environmental education has built a conduct in the society in relation to natural resources, which contributes to the development of sustainable tourism. It is concluded that sustainable tourism in protected areas can be an assistant in the process of balanced development, from educational practices involving environmental nature, society and culture.
\end{abstract}

Key words: Environmental education; Sustainable tourism; Maracanã Environmental Protection Area (APA).

\footnotetext{
* Graduação em Turismo pela Faculdade Atenas Maranhense. Especialização em Turismo: planejamento, gestão e marketing pela Universidade Católica de Brasília. Mestrado em Administração e Desenvolvimento Empresarial pela Universidade Estácio de Sá. Professor do Departamento de Turismo e Hotelaria e do Curso de Administração (Virtual) da Universidade Federal do Maranhão (UFMA). Endereço: Rua Minerva, 9, Quadra. 27, ap. 501, Renascença 2. CEP: 65075-035 - São Luís - Maranhão (Brasil). Telefax: (98) 8181-0228. E-mail: saulosantosma@uol.com.br

** Graduação em Relações Públicas (UFMA). Mestrado em Comunicação pela Universidade Federal do Rio de Janeiro (UFRJ). Doutorado em Desenvolvimento Sustentável do Trópico Úmido, com área de concentração em Ciências Ambientais pela Universidade Federal do Pará (UFPA). Professor no Curso de Comunicação Social (UFMA). Professor na Universidade Estadual do Maranhão no Departamento de Ciências Sociais e no Mestrado em Desenvolvimento Socioespacial e Regional. Endereço: Rua Minerva, 9, Quadra 27, ap. 501, Renascença 2. CEP: 65075-035 - São Luís - Maranhão (Brasil). Telefax: (98) 8114-6015. E-mail: labcom17@ bol.com.br
} 


\section{INTRODUÇÃO}

Um dos assuntos que mais ocupam a mídia de um modo geral é a questão ambiental, pois a preservação do meio ambiente tornou-se uma questão que vem fazendo parte das sociedades, governos e empresas, devido ao crescimento da consciência ecológica por parte destes.

Surgem assim, inúmeros debates a respeito do tema e também pelas inquietações políticas na busca de um desenvolvimento que seja harmonioso com os recursos naturais e que promova qualidade de vida na população, ou seja, a busca pelo desenvolvimento sustentável.

Mas, para que se possa alcançar esse tipo de desenvolvimento faz-se necessário incentivar o cidadão a assumir posturas mais críticas para poder questionar de forma concreta a falta de iniciativas por parte de alguns governos em implementar políticas voltadas para a conservação do meio ambiente não deixando de lado a inclusão da população. Com isso, a educação ambiental tem sido vista como uma ferramenta essencial para a consolidação dessas atitudes na medida em que educa o cidadão através de programas e projetos exeqüíveis, onde são envolvidos todos os níveis (faixa etária, renda) da comunidade local.

Além disso, o turismo surge como uma atividade catalisadora capaz de aliar sustentabilidade ao desenvolvimento, a partir do momento em que esta, quando bem planejada e incentivada, passa a trabalhar e executar os princípios da sustentabilidade, visando minimizar os impactos que a atividade exerce sobre um determinado local.

Portanto, compreendendo estes quesitos chega-se ao objetivo geral desta pesquisa que consistiu em analisar como a educação ambiental poderia contribuir para o desenvolvimento de uma prática do turismo sustentável na Área de Proteção Ambiental do Maracanã, situada no estado do Maranhão (Brasil). Para a elaboração do estudo, utilizou-se de pesquisa bibliográfica, documental e visita no bairro Maracanã (empírica), realizada no mês de novembro de 2008. Os dados desta pesquisa dão subsídios para novas pesquisas, incluindo temas recentes ligados às ações da Prefeitura na localidade atualmente.

Partindo dessas premissas, considera-se relevante a realização deste trabalho, visto que o Maracanã é um bairro que se caracteriza por uma grande diversidade de 
atrativos ambientais, culturais e históricos, fazendo parte de uma Área de Proteção Ambiental (APA) e que muitas vezes se encontra ameaçado pela falta de infraestrutura, de apoio por parte de alguns órgãos públicos e que vive à mercê do Parque Industrial de São Luís que se encontra a poucos quilômetros do bairro.

\section{O DESENVOLVIMENTO SUSTENTÁVEL E O PARADIGMA AMBIENTAL}

Vive-se em uma sociedade onde o consumo exacerbado tem instigado um novo modelo de desenvolvimento, no qual se têm agravadas as desigualdades sociais e a degradação ambiental e está sendo fomentada há muito tempo pelos países, principalmente os do hemisfério Sul, que vêem na industrialização a "solução" para os problemas que assolam seus territórios, tais como a pobreza, o analfabetismo, as desigualdades sociais, o saneamento básico, entre outros.

Sendo assim, conservação ambiental e desenvolvimento econômico freqüentemente têm sido vistos como interesses antagônicos. Aliá-los não tem sido uma tarefa fácil, as tentativas decorrem de séculos atrás, mas ainda é expressivo o número de pessoas que, por falta de informação ou desinteresse, não compreendem que a conservação ambiental leva a uma melhoria da qualidade de vida.

Entretanto, influenciados pelo movimento ambientalista que emergiu nos anos 70 e diante de catástrofes que vem ocorrendo, tais como furacões, enchentes, grandes secas, além de destruição de ecossistemas, aquecimento global, aumento do nível do mar pelo derretimento de calotas polares, - cuja explicação deriva de ações antrópicas realizadas ao longo dos anos - esse pensamento tem mudado cada vez mais, visto que, tais catástrofes podem resultar em uma falência da humanidade. (ANDRADE, 2001).

Nos anos 60, o debate sobre a crise ecológica global teve um grande impulso com o Clube de Roma (1968), que foi uma reunião realizada por trinta especialistas de diversas áreas, tais como humanistas, industriais, economistas, pedagogos, para discutir e analisar os limites do crescimento econômico levando em conta o uso crescente dos recursos naturais pelo crescimento exponencial da população (ANDRADE, 2001). Por ter chamado a atenção do mundo com suas observações, essa reunião se tornou um marco do debate mundial sobre a problemática do meio ambiente e seu caráter global. 
Dias (2003) ratificou que o aumento populacional, a escassez de alimentos e o progresso tecnológico eram os grandes responsáveis pela crise ambiental.

Apesar das conclusões emitidas por essa reunião serem consideradas por muitos como "alarmistas", pois foi fundamentada na Teoria Neomalthusiana, é patente que o aumento populacional provoca mudanças no meio ambiente, visto que se necessita de mais infraestrutura e alimentos para suprir a quantidade crescente de pessoas e na maioria das vezes essas mudanças não seguem planejamento algum, causando "inchaço" nas cidades e impactos no meio ambiente natural.

Estes impactos são: aumento da quantidade de lixo, poluição dos rios, desmatamento na busca de mais espaço, favelização, impondo, cada vez mais, pessoas a viverem em condições subumanas, principalmente as mais pobres que, desprovidas de condições financeiras, não têm possibilidade de escolher para viver nos espaços urbanos que apresentam melhores condições de moradia (DIAS, 2004).

Todavia, as propostas adotadas pela reunião (Clube de Roma em 1968) eram tidas como inaceitáveis e se tornaram alvo de muitas críticas de políticos que interpretaram que era necessário controlar o crescimento populacional dos países do $3^{\circ}$ mundo para conservar o padrão de vida dos países do $1^{\circ}$ mundo, ou seja, condenavam os países mais pobres, que ainda não haviam experimentado o patamar de industrializados, a resolver impasses ecológicos resultantes do desenvolvimento dos países mais ricos (MARGULIS, 1996).

Essa teoria estabelecia o "crescimento populacional zero" a fim de instituir um equilíbrio no consumo dos recursos naturais, porém, apesar de rejeições por parte de tais políticos, causou respaldo aos debates que estariam por vir, inclusive na conferência que se realizaria na Suécia em 1972.

Porém, o problema não está na quantidade de pessoas, mas, na relação entre esse número e os recursos disponíveis. Assim, para resolver o "problema populacional", são necessários esforços para eliminar a pobreza, a fim de que seja garantido o acesso eqüitativo aos recursos naturais e através da educação, incentivar nessas pessoas um potencial capaz de gerir os recursos naturais (COMISSÃO MUNDIAL DO MEIO AMBIENTE E DESENVOLVIMENTO, 1991).

Sendo assim, evidencia-se a necessidade de desenvolver uma consciência ecológica na sociedade que seja capaz de cobrar ações de forma concreta, por parte dos 
governos que sejam capazes de acabar com a pobreza e ao mesmo tempo, educar os cidadãos para serem agentes multiplicadores da conservação ambiental.

A Conferência de Estocolmo, como ficou conhecida a Conferência das Nações Unidas sobre o Meio Ambiente Humano - não por acaso realizada na Suécia que havia sofrido sérios danos em milhares de seus lagos, em consequiência de chuvas ácidas resultantes da forte poluição atmosférica na Europa Ocidental - colocou o meio ambiente no foco das preocupações internacionais (ANDRADE, 2001). Essa conferência gerou a Declaração sobre o Ambiente Humano, uma lista de Princípios e um Plano de Ação Mundial. Esse plano teve como objetivo "orientar a preservação e a melhoria no ambiente humano" (DIAS, 2003, p. 33). Outro fato importante dessa conferência foi a criação do Programa das Nações Unidas sobre o Meio Ambiente PNUMA (O QUE É PNUMA?, 2008), que tem por objetivo unir as Nações para que enfrentem os problemas comuns, buscando o equilíbrio entre interesses nacionais e o bem estar global (ANDRADE, 2001). Isso, haja vista, o desequilíbrio ambiental e social em que se encontravam os países, refletindo assim, um mundo desigual e predatório.

Desse modo, na busca de um modelo de desenvolvimento mais harmônico, surgiu nessa conferência o termo "ecodesenvolvimento", que mais tarde seria ampliado e amadurecido por Ignacy Sachs e posteriormente, aprimorado e renomeado como "Desenvolvimento Sustentável” (ANDRADE, 2001, p. 3). Segundo Santilli (2005), o denominado Relatório Brundtland oriundo dessa conferência, incorporava não só o componente ambiental como também o social, ao conceito de desenvolvimento sustentável, demonstrando que o mesmo deveria ser viável para os três componentes que orientam seu conceito, que são a eqüidade social (desenvolvimento social), a proteção ambiental (preservação ambiental) e o crescimento econômico (desenvolvimento econômico).

Apesar da Conferência de Estocolmo ter lançado as bases do desenvolvimento sustentável, ele só veio ganhar respaldo em abril de 1987, no documento denominado Nosso Futuro Comum. Nesse Relatório foi anunciado pela primeira vez o conceito de desenvolvimento sustentável, que é utilizado até hoje, sendo definido como "aquele que atende às necessidades do presente sem comprometer a possibilidade de as gerações futuras atenderem a suas próprias necessidades." (COMISSÃO MUNDIAL DO MEIO AMBIENTE E DESENVOLVIMENTO, 1991, p. 46). 
De acordo com Dias (2004), esse documento foi elaborado pela Comissão Mundial sobre o Meio Ambiente e o Desenvolvimento (CMMAD) ${ }^{1}$, criada pela Organização das Nações Unidas (ONU) e presidida pela primeira-ministra da Noruega Gro Brundtland, razão pela qual o documento ficou conhecido como Relatório Brundtland.

Para Dias (2003, p. 35), esse relatório,

[...] pode ser considerado um dos mais importantes documentos sobre a questão ambiental e o desenvolvimento dos últimos anos. Vincula estreitamente economia e ecologia e estabelece com muita precisão o eixo em torno do qual se deve discutir o desenvolvimento, formalizando o conceito de desenvolvimento sustentável e estabelecendo os parâmetros a que os Estados, independente da forma de governo, deveriam se pautar, assumindo a responsabilidade não só pelos danos ambientais como também pelas políticas que causam esses danos.

Ou seja, esse relatório procurou estabelecer metas a serem atingidas em nível planetário apontando a forma insustentável com que os países estavam gerindo seus recursos, devendo os mesmos incorporar a sustentabilidade em todos os aspectos políticos na busca de um modelo de desenvolvimento que consiga aliar conservação ambiental e avanço tecnológico.

Assim, o relatório buscava conciliar ao avanço tecnológico, não só a conservação ambiental como também a integridade social quando afirmava que para haver um desenvolvimento sustentável, deve-se primeiramente atender às necessidades básicas da população tais como alimentação, moradia, saneamento; para depois dar oportunidades de realizar suas aspirações a uma vida melhor, pois uma sociedade onde a pobreza é patente estará sempre sujeita a todo tipo de catástrofe, seja ela ecológica ou não (COMISSÃO MUNDIAL DO MEIO AMBIENTE E DESENVOLVIMENTO, 1991, p. 9-10).

Apesar do conceito de desenvolvimento sustentável ter se efetivado somente quinze anos após a Conferência de Estocolmo, esta se consolidou por ter sido um marco importante na discussão ambiental e ter chamado a atenção do mundo quanto às questões de desenvolvimento e meio ambiente, porém gerou muita polêmica entre representantes de diversas nações.

\footnotetext{
${ }^{1}$ A Comissão Mundial sobre o Meio Ambiente e o Desenvolvimento (CMMAD), tinha como objetivo "examinar as relações entre meio ambiente e o desenvolvimento e apresentar propostas viáveis" (DIAS, 2003, p. 35).
} 
Visto que, o modelo de desenvolvimento capitalista vigente, não está conseguindo solucionar os problemas básicos da população como miséria, fome, analfabetismo, saneamento, e, além disso, deteriora o meio ambiente, é preciso buscar um modelo de desenvolvimento baseado na sustentabilidade.

Contudo, para que seja alcançada essa sustentabilidade é necessário:

[...] o desenvolvimento de uma nova geração de valores e de conceitos, de metodologia e instrumentos, todos eles congruentes entre si, para conformar um paradigma emergente em relação ao tradicional, que sacrifica a sustentabilidade aos rendimentos econômicos e financeiros, sobre a base de uma tecnologia que não é apropriada para o meio ambiente (MOLINA, 2001, p. 180).

Sendo assim, esse novo paradigma que vem sendo preconizado para que seja alcançada a sustentabilidade tem sido denominado como paradigma ambiental. (MININNI-MEDINA, 2001).

\section{CONCEPÇÕES SOBRE EDUCAÇÃO AMBIENTAL}

O racionalismo cartesiano via a natureza como um objeto a ser dominado pela razão humana, devendo ser trabalhada de forma fragmentada, ou seja, estudando suas partes de forma isolada para se chegar à compreensão do todo. Esse pensamento mecanicista influenciou por muito tempo a definição de meio ambiente e a compreensão e alocação da educação ambiental.

O meio ambiente deve ser visto como um conjunto dos fatores bióticos (flora, fauna) e abióticos (água, ar, solo, energia), que interagem com a cultura humana (seus valores morais, filosóficos, artísticos, políticos, econômicos), buscando uma relação dinâmica e equilibrada. Essa interação "busca assumir uma concepção unitária do ambiente compreensiva dos recursos naturais e culturais" (SILVA, 1995, p. 2 apud SANTILLI, 2005, p. 71) ${ }^{2}$ para só assim ser desenvolvida uma relação harmônica entre o homem e a natureza.

De acordo com Dias (2004), essa concepção de meio ambiente incluindo a cultura humana foi influenciada pela Conferência de Estocolmo, onde o meio ambiente

\footnotetext{
${ }^{2}$ SILVA, J. A. da. Direito ambiental constitucional. São Paulo: Malheiros, 1995.
} 
é definido como "o sistema físico e biológico global em que vivem o homem e outros organismos - um todo complexo com muitos componentes interagindo em seu interior". (MARGULIS, 1996, p. 13).

Foi também, nessa Conferência que a educação ambiental (EA) passou a ganhar respaldo em âmbito planetário, sendo reconhecida pela primeira vez como essencial para solucionar a crise ambiental internacional. Pois, se tornou necessária a implementação de uma educação que instigasse nos indivíduos a capacidade de responder aos desafios impostos pelo modelo de desenvolvimento vigente.

Tendo em vista que educar significa gerar no indivíduo uma consciência crítica em relação aos seus direitos e deveres, preparando-o para viver em sociedade e capacitando-o para compreender adequadamente o meio em que está inserido, o princípio $n^{\circ} .19$ dessa Conferência assinala que:

É indispensável um trabalho de educação em questões ambientais dirigido tanto às gerações jovens como aos adultos, e que preste a devida atenção ao setor da população menos privilegiada, para ampliar as bases de um opinião bem informada e de uma conduta dos indivíduos, das empresas e da coletividade, inspirada no sentido de sua responsabilidade quanto à proteção e melhoramento do meio em toda sua dimensão humana (MININNIMEDINA, 2001, p. 19).

Ou seja, uma educação que abarque todos os indivíduos dos vários setores da sociedade, de diferentes idades, principalmente os de classe social mais baixa, pois geralmente são os que têm menos acesso aos recursos, propiciando um conhecimento acerca da realidade política, social e econômica em nível global, gerando assim, no indivíduo uma atitude crítica em relação às políticas públicas ambientais e atitudes responsáveis diante do meio ambiente.

Dois anos mais tarde, foi promulgada a Política Nacional de Educação Ambiental (BRASIL, Lei Federal 9.795/99), que define em seu art. $1^{\circ}$, a educação ambiental como:

[...] os processos por meio dos quais o indivíduo e a coletividade constroem valores sociais, conhecimentos, habilidades, atitudes e competências voltadas para a conservação do meio ambiente, bem de uso comum do povo, essencial à sadia qualidade de vida e sua sustentabilidade $\left(\operatorname{art} .1^{\circ}\right)$.

Percebe-se com essa definição, que a educação ambiental se constitui numa forma abrangente de educação, onde o objetivo é promover ao cidadão novas formas de 
conduta e um maior conhecimento do meio em que está inserido, tornando-o apto para agir na busca de soluções para os problemas ambientais e consequentemente para uma melhoria na qualidade de vida.

A educação ambiental deve então, contribuir para que os cidadãos desenvolvam conhecimento a respeito dos problemas ambientais, atualizando-os com informações importantes que estão sendo discutidas em todo o mundo pelos cientistas, humanistas, educadores, para então, adquirir capacidade de julgar a qualidade dos serviços públicos implementados.

Além disso, o homem a partir da educação ambiental deve desenvolver habilidades para atuar como agente transformador participando de forma responsável e eficaz na proteção do meio ambiente, objetivando então, construir um mundo mais humano e sustentável.

\section{TURISMO SUSTENTÁVEL}

A forma predatória com que a atividade turística vinha utilizando os recursos naturais foi questionada pela nova consciência ecológica que surgia no final da década de 60 e início de 70, resultando, segundo Dias (2003), na procura por alternativas a essa forma de turismo, principalmente nos anos $80 \mathrm{com}$ o crescimento do movimento ambientalista.

Com isso, essa atividade começou a ser influenciada pelas conferências, encontros e debates que estavam acontecendo no mundo. Sendo assim, foi realizada em 1995, a Conferência Mundial de Turismo Sustentável em Lanzarote, Ilhas Canárias, Espanha, onde segundo Dias (2003) objetivava suprir a necessidade de incorporar os princípios estabelecidos pela Eco-92, além das recomendações da Agenda 21, que já tratava do assunto, porém, de forma superficial em três capítulos, 11, 13 e 14 .

$\mathrm{O}$ autor elucida que o primeiro artigo dentre os dezoito que foram estabelecidos nessa conferência, deixa claro que o desenvolvimento turístico deve fundamentar-se em critérios de sustentabilidade (Figura 1), quando afirma que a atividade "deverá ser suportável ecologicamente a longo prazo, viável economicamente e eqüitativo desde uma perspectiva ética e social para as comunidades locais" (DIAS, 2003, p. 60). 


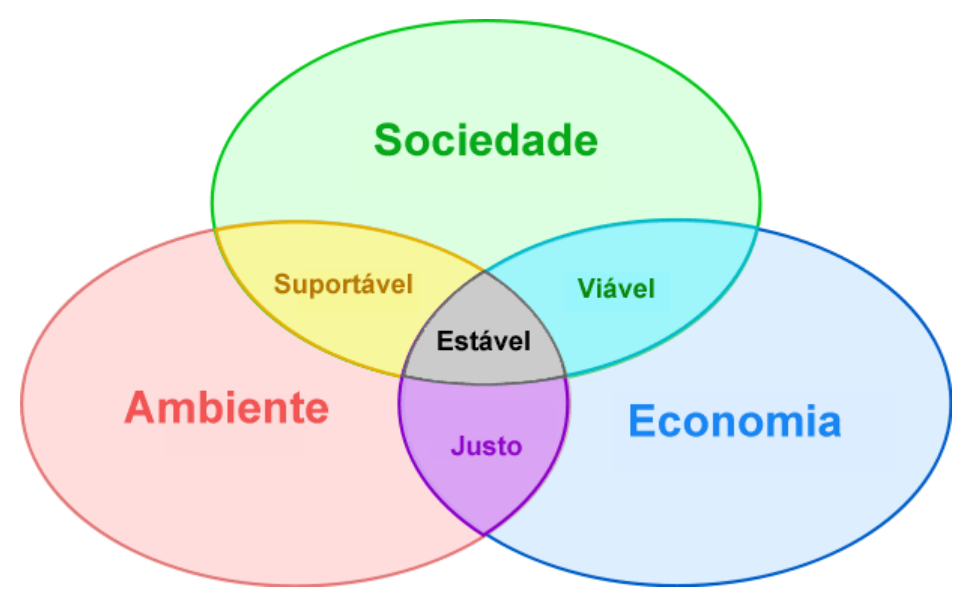

FIGURA 1: TRIPÉ DO DESENVOLVIMENTO SUSTENTÁVEL

FONTE: TRIPÉ (2008).

Desse modo, o turismo deve adotar o tripé do desenvolvimento sustentável, haja vista a importância dessa atividade na promoção e no estabelecimento dos princípios que orientam esse modelo de desenvolvimento.

Diante dessa analogia, a Organização Mundial do Turismo (OMT) baseando-se no relatório Brundtland, estabelece a definição da atividade turística sustentável como aquela que:

\begin{abstract}
Atende às necessidades dos turistas de hoje e das regiões receptoras, ao mesmo tempo em que protege e amplia as oportunidades para o futuro. É visto como um condutor ao gerenciamento de todos os recursos, de tal forma que as necessidades econômicas, sociais e estéticas possam ser satisfeitas sem desprezar a manutenção da integridade cultural, dos processos ecológicos essenciais, da diversidade ecológica e dos sistemas que garantem a vida (OMT, 2003, p. 35).
\end{abstract}

Sendo assim, o turismo sustentável é uma maneira de praticar o turismo levando em conta as necessidades das localidades e dos turistas, de maneira que não comprometa a qualidade de vida da população, compreendendo os sistemas sociais, culturais e econômicos e protegendo o meio ambiente para as próximas gerações.

\title{
5 ÁREA DE PROTEÇÃO AMBIENTAL DO MARACANÃ
}

A Área de Proteção Ambiental (APA) do Maracanã encontra-se na área de São Luís que segundo o Instituto Brasileiro de Geografia e Estatística (IBGE, 2011) é uma 
cidade que conta com um contingente populacional de 1.014.837 habitantes, sendo considerada a $15^{\mathrm{a}}$ cidade mais populosa do Brasil, situada na região Nordeste do Brasil (figura 1), posicionada em uma ilha com $831,7 \mathrm{~km}^{2}$ (figura 2). Sua localização é estratégica, pois está na divisa das regiões Norte e Nordeste, por isso apresenta diversidade natural como mangues, dunas, praias, rios, floresta Amazônica e floresta de Babaçu.
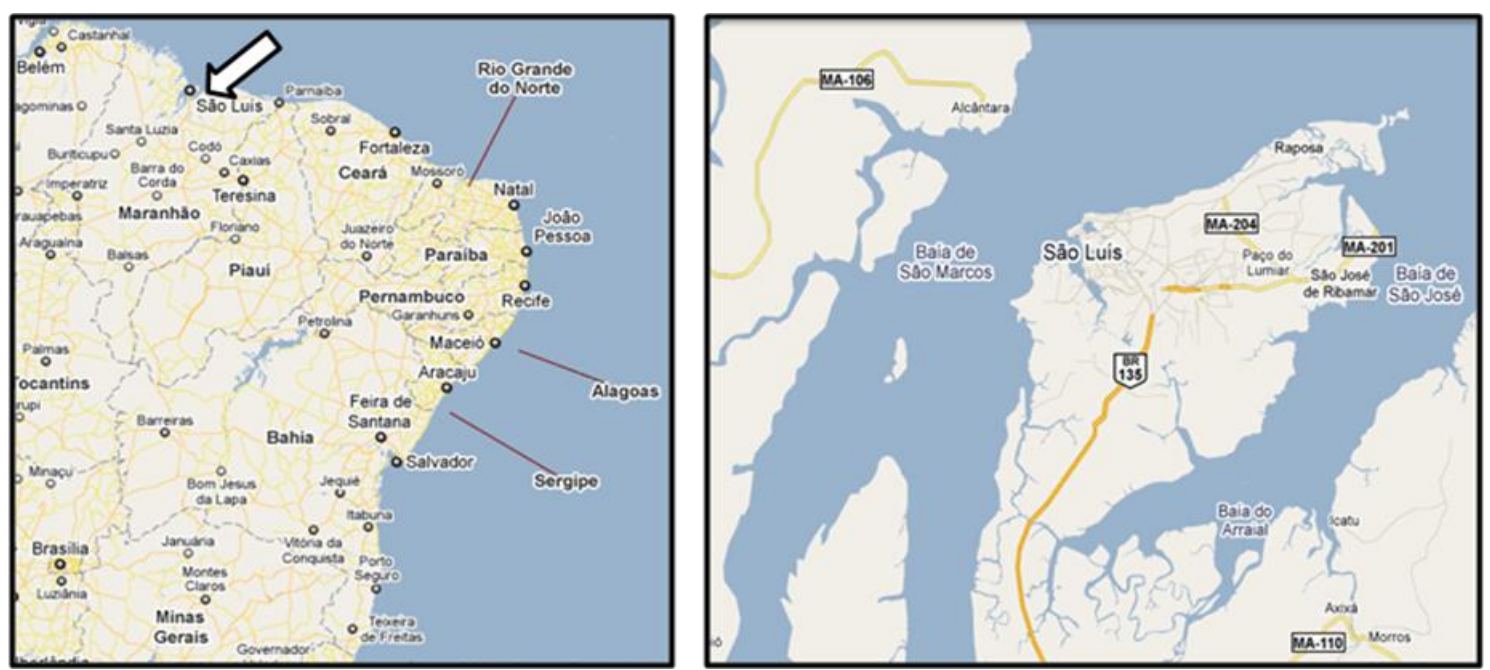

FIGURAS 1 e 2 - MAPAS DE LOCALIZAÇÃO DE SÃO LUÍS NO BRASIL

FONTE: GOOGLE MAPS (2011)

Por sua vez, o Maracanã é um bairro da zona rural de São Luís, que se caracteriza pela diversidade de atrativos naturais, culturais e históricos. E juntamente com os bairros Vila Maranhão, Vila Esperança, Vila Sarney e Rio Grande formam a Área de Proteção Ambiental do Maracanã (figura 3), que foi criada por meio de Decreto Estadual $n^{\circ}$. 12.103/1991 (CHAVES, 2007). Sendo assim, o governo do Maranhão percebendo a fragilidade dessa área e a ameaça de degradação que a mesma sofria por ações antrópicas e devido ao crescimento do Parque Industrial de São Luís foi então decretada como uma unidade de conservação.

A Área de Proteção Ambiental do Maracanã apresenta uma extensão de 1.831 hectares, e limita-se ao norte pelo Parque Estadual do Bacanga, a oeste pelo Módulo 9 do Distrito Industrial de São Luís, ao leste pela estrada BR-135, e ao sul pela localidade do Rio Grande (CHAVES, 2007).

Seu percurso, de apenas de $25 \mathrm{~km}$ do centro da cidade de São Luís, é asfaltado necessitando, no entanto, de melhoria na sinalização. 


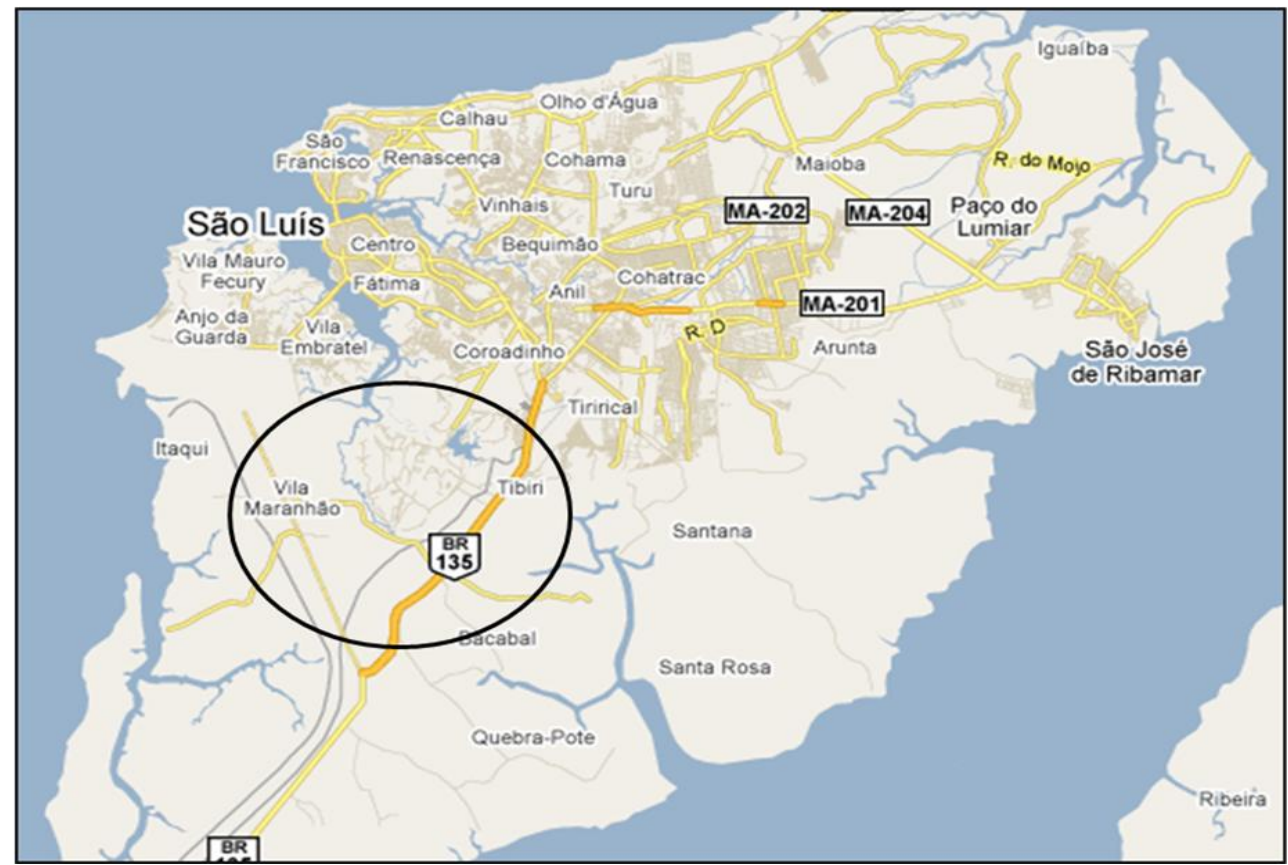

FIGURA 3 - MAPA DA ILHA DE SÃO LUÍS COM DESTAQUE PARA A APA DO MARACANÃ. FONTE: GOOGLE MAPS (2011)

Na APA existiram projetos de educação ambiental que foram desenvolvidos tanto por iniciativa de escolas, como também por parte do poder público, mais precisamente pela Secretaria Municipal de Turismo (SETUR), conforme segue:

1) Centro Educacional Sagrado Coração de Jesus (CESCO): é uma escola privada mantida pela senhora Carminda Guimarães, esposa do falecido Joca Guimarães, que executa atividades educativas iniciadas pelo marido. Se configura como uma escola que pratica ações voltadas à conservação do meio ambientais. Onde parte dos responsáveis dos alunos fazem o pagamento da mensalidade através de doações de frutas, roupas, mantimentos ou os mais diversos serviços como limpeza, manutenção, entre outros. Dentro da escola, que se destaca por possuir áreas verdes, com espécies de flora típica da região, são desenvolvidos cinco projetos objetivando a conscientização e construção de uma consciência ecológica nos alunos, sendo: O lixo como perspectiva de transformação ambiental; Manhã Criança Feliz; Fazendo Cultura; Amigos da Natureza; Operação Formiguinha (CHAVES, 2007, p. 40);

2) Escola Augusto Mochel: Protetores da Vida: atividades de educação ambiental em disciplinas para crianças do ensino fundamental;

3) Projeto Maracanã: foi lançado pela Prefeitura de São Luis, através da Secretaria Municipal de Turismo (antiga FUMTUR) no ano 2000, objetivando a utilização sustentável dos recursos naturais e culturais do bairro do Maracanã, ampliando a oferta de lazer e promovendo a geração de trabalho, renda e qualidade de vida para a comunidade (ARAÚJO, 2007, p. 15) O projeto possui três linhas de atuação: a social, composta de palestras temáticas, como saúde humana, educação ambiental, agrícola, atendimento, cidadania e empreendedorismo. A cultural, através de resgate das 
manifestações culturais do bairro como o tambor de crioula, o bumba-meuboi, festa da juçara, Divino Espírito Santo, entre outros, além de incentivo à produção e comercialização de produtos locais, gastronomia e artesanato. E a ação ambiental que visa à conservação dos recursos naturais, através de campanhas de sensibilização ambiental, plantio de mudas e algumas atividades educacionais como a reciclagem e aproveitamento do lixo, além da execução das trilhas (ARAÚJO, 2007, p. 28), que são "guiadas hoje por 19 agentes ambientais todos moradores do bairro e selecionados pelo projeto" (CHAVES, 2007, p. 40).

Tais projetos de educação ambiental trouxeram resultados positivos durante a sua execução e por um período de 5 anos, sendo que hoje estes projetos não vigoram, com exceção do CESCO que ainda realiza atividades de educação ambiental. E as trilhas do Maracanã estão abandonadas.

\section{A EDUCAÇÃO AMBIENTAL E SUA CONTRIBUIÇÃO PARA O TURISMO SUSTENTÁVEL NA APA DO MARACANÃ}

A coleta de dados deu-se entre os dias 15 e 19 de novembro de 2008, na APA do Maracanã, junto aos moradores, principalmente nas ruas próximas aos colégios e ao parque da Juçara. O universo da pesquisa totalizou a comunidade residente do bairro do Maracanã, sendo que a amostra determinada foi um total de 100 pessoas. A escolha se deu por forma aleatória, por julgar-se que fosse interessante ter uma amostra diversificada das concepções dos moradores residentes no Maracanã. A análise foi quantitativa e qualitativa.

Primeiramente, questionou-se a respeito da percepção dos moradores em relação à atividade turística no Maracanã, ou seja, de que forma eles viam o turismo acontecendo na região. Sendo que $68,69 \%$ responderam de forma positiva e $31,31 \%$ responderam de maneira negativa, ou seja, o turismo, na visão dos moradores da APA estava sendo benéfico para a grande maioria deles. Mas isso se deu pelas ações que foram realizadas a partir de 2000, pela Secretaria Municipal de Turismo.

Os respondentes que manifestaram estar satisfeitos com a atividade que estava sendo desenvolvida, justificaram as respostas mencionando que esta trazia renda e promovia a identidade da comunidade, ajudando assim a desenvolvê-la economicamente e a conservar os recursos naturais e culturais. 
Boa parte dos moradores associou a questão do turismo, à Festa da Juçara, referindo-se a esta como a maior responsável pelo fluxo de visitantes. Quanto às pessoas que responderam negativamente, a justificativa deu-se em relação à falta de iniciativa de órgãos públicos para melhorar o desenvolvimento da atividade, de interesse dos próprios turistas que ou não apresentavam interesse em conhecer a localidade ou porque não eram estimulados para tal, sendo assim, o afluxo de pessoas era justificado como fraco, principalmente devido à falta de divulgação, em especial da Festa da Juçara. Entende-se que o turismo ao mesmo tempo em que promove mudanças positivas, também contribui de maneira negativa, portanto, verificou-se haver a necessidade de um ordenamento e integração de todos os envolvidos, para manter a "alma do lugar", preservando a identidade cultural da APA do Maracanã e da sua festa (principal produto turístico do local), e também incentivando o desenvolvimento na região.

Em seguida, questionou-se sobre o conhecimento dos moradores a respeito de quanto tempo a atividade turística vinha sendo desenvolvida na região (gráfico 1).

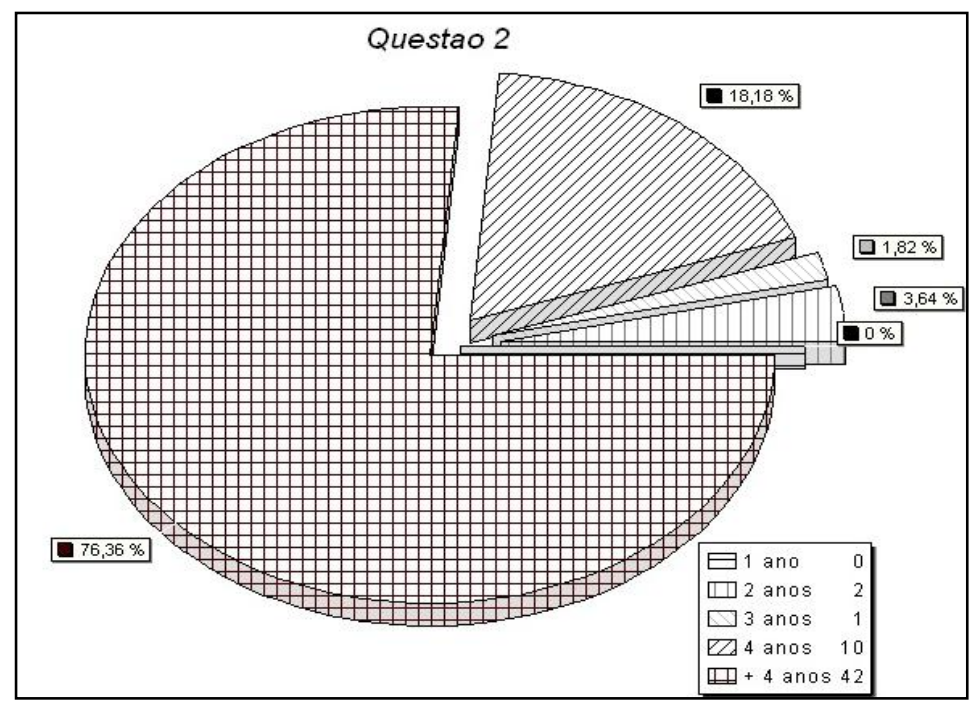

GRÁFICO 1 - TEMPO DE DESENVOLVIMENTO DA ATIVIDADE TURÍSTICA NA REGIÃO FONTE: PESQUISA DE CAMPO (2008)

Como a aplicação foi aleatória, verificou-se uma variação do conhecimento sobre a existência da atividade turística na localidade, sendo que 77\% dos entrevistados responderam mais de quatro anos e $18,18 \%$ afirmaram que o turismo vinha acontecendo 
há 4 anos na região. Somando estes resultados, teve-se um total de 95,18\%, que correspondeu quase que à totalidade da porcentagem.

Em seguida, questionou-se a opinião dos moradores sobre a importância da APA do Maracanã para o turismo. Cerca de $80 \%$ responderam que sabiam a importância da APA para o turismo, justificando que o fato de ser área protegida estimulava ainda mais a atração de turistas, além de contribuir para a conservação dos recursos, dada a importância atribuída à região e conseqüentemente, conscientizava a população e o visitante a respeito do meio ambiente. Como complemento traz-se uma citação de um dos entrevistados: "Sim, pois são pessoas que vêm prestigiar nosso lugar e trazer muitos benefícios e é uma maneira de divulgar o Maracanã”.

Esta concepção sobre a importância da APA para o turismo mostrou que os moradores estavam abertos para a atividade turística, pois, acreditavam ser a mesma um fator de desenvolvimento, conforme colocado anteriormente na questão 1. Portanto, entendeu-se que o turismo deveria ser desenvolvido de forma equilibrada, respeitando os aspectos naturais e a própria legislação da unidade de conservação no que tange à APA, para que o Maracanã mantivesse preservada sua paisagem natural.

Já outros 20,41\% não souberam responder a importância que a APA possuía para a atividade turística. Deixando clara então, a necessidade de realizar um processo de conscientização com essa parcela da população quanto à atividade turística.

Em seguida, complementando a questão anterior, questionou-se sobre a importância da APA para a comunidade, pois se entendeu necessário ter a percepção dos autóctones sobre sua participação no processo da atividade turística. A maioria das pessoas $(81,61 \%)$ reconheceu a importância da APA para a comunidade, justificando que o fato de ser uma área protegida podia evitar a depredação da flora, tais como as árvores frutíferas que tinham importância para a economia local como os juçarais, pois muitos estavam vivendo da venda dos derivados desta fruta, além de manter uma salutar área natural para a prática de lazer para a comunidade e consequientemente mais qualidade de vida para a mesma, bem como conscientização da própria população e o engajamento em ações de preservação do meio ambiente. Como complemento traz-se uma citação de um dos entrevistados: "Favorece o crescimento da renda aos moradores que vendem juçara". 
Esta compreensão sobre a importância da APA se deu também pelos projetos ambientais desenvolvidos pela esfera pública municipal, através de oficinas e ações em prol da educação ambiental, que serviram e servem para o amadurecimento sobre como as unidades de conservação auxiliam no desenvolvimento sustentável de uma localidade.

Por outro lado, os 19,39\% restantes, responderam que não sabiam a importância da APA para a comunidade. As pessoas que residem em áreas de conservação devem estar conscientes de seu papel como contribuintes para o processo de preservação da mesma. Para tanto, é necessário um investimento dos setores público, privado e terceiro setor, para auxiliar os moradores a perceberem de que forma eles podem se beneficiar e vice-versa com os recursos naturais existentes no Maracanã.

Em seguida, perguntou-se aos moradores se já tinham participado de algum curso de educação ambiental. A maior parte, $71 \%$, mencionou que nunca havia participado de cursos a respeito de educação ambiental. Essa afirmação se justificou pelo fato da maioria dos entrevistados não entenderem o significado de uma UC e, muitos ao serem abordados não sabiam o que era área de proteção ambiental e outros ainda, que o bairro onde residiam era uma área protegida. A desinformação por parte destes foi patente.

Os que sabiam e tinham opiniões concretas a dar a respeito, em sua maioria eram os que já haviam participado de cursos de educação ambiental, totalizando $29 \%$ dos entrevistados. Estes, quando questionados sobre qual foi a contribuição dada pelo curso de EA que haviam participado, as respostas que prevaleceram foram o fato de obterem uma maior conscientização em relação ao meio ambiente, bem como uma compreensão crítica a respeito deste, além de práticas como plantio de mudas, reciclagem de lixo, e de como revitalizar os rios, já que muitos dos sítios de moradores estavam localizados nas proximidades dos rios que cortam a região.

Portanto, a educação ambiental havia conseguido se efetivar no cotidiano desses moradores em uma prática e um estilo de vida sustentável, corroborando assim, com uma das recomendações da conferência de Tbilisi, realizada em 1977 (ANDRADE, 2001), na qual se destaca que a educação ambiental deve provocar uma conexão mais estreita entre os processos educativos e a realidade, estruturando suas atividades em torno dos problemas concretos que se aplicam à comunidade; e focalizar a análise de 
tais problemas, através de uma perspectiva interdisciplinar e globalizadora, que permita uma compreensão adequada dos problemas ambientais.

Obteve-se que $61,11 \%$ dos respondentes concordaram que os projetos realizados na área de educação ambiental tinham contribuído para a preservação da APA do Maracanã. Justificaram que tais projetos auxiliaram para a conservação dos rios, da flora e fauna. Como complemento traz-se o depoimento de dois dos entrevistados: "Sim, pois é uma forma de passar conhecimento para as pessoas" e "A diminuição das queimadas e do desmatamento".

Essa questão esteve relacionada com a recomendação de número 7 da Conferência de Tbilisi, que adverte que a educação ambiental deve ter por finalidade a criação de uma consciência que busque conservar a biosfera, melhorar a qualidade de vida e salvaguardar valores éticos, bem como o patrimônio cultural e natural. Sendo assim, evidenciou-se ser a educação ambiental uma ferramenta essencial para a manutenção e conservação dos recursos naturais existentes em unidades de conservação.

Os outros quase $39 \%$ discordaram, acreditando que os projetos realizados não tinham contribuído para a conservação da APA, entretanto, quando perguntado o motivo, a maioria respondeu que não conheciam nenhum projeto de educação ambiental, até o pesquisador mencionar sobre o Projeto Maracanã que incluía as trilhas ecológicas. Somente assim, alguns lembravam, mas como não conheciam a atuação deste, portanto, respondiam de forma negativa.

No que diz respeito à contribuição dos projetos realizados na área de educação ambiental para a efetivação de uma consciência ecológica na comunidade, apenas $53,33 \%$ dos respondentes afirmaram positivamente em relação à questão, justificando as respostas pelo fato de terem obtido um conhecimento maior a respeito da importância de conservar a APA, passando a valorizá-la mais, além do aumento do número de jovens engajados no assunto. Como complemento, no entendimento de um entrevistado, este esclareceu que: "Sim, pois nós temos aprendido ao longo dos dias um pouco mais sobre o que fazer com o lixo, a não sujar os rios [...]".

Porém, foi considerável o número de pessoas que responderam negativamente, correspondendo a aproximadamente $47 \%$, onde a maioria das justificativas dava-se pelo 
fato de considerarem que muitas pessoas ainda desmatavam árvores para construção civil e não estavam de fato preocupadas com a questão.

Foi proeminente o número de pessoas que disseram contribuir para a preservação da APA do Maracanã, sendo 62\% dos entrevistados, isso se comparado com o fato de muitos nunca terem participado de cursos de educação ambiental, totalizando $71 \%$ dos entrevistados. Quando perguntado de que forma eles haviam contribuído, as respostas que prevaleceram foram: fazendo o plantio de mudas em áreas devastadas, doação de materiais para reciclagem, não jogando lixo nem fazendo queimadas ou derrubadas de árvores. Vale ressaltar que algumas dessas contribuições foram feitas por moradores que participavam de projetos de EA em conjunto com a comunidade e outros individualmente.

Ressalta-se que segundo Wells e Brandon (1992 apud KINKER, 2002) $)^{3}$ para a efetiva manutenção da diversidade biológica é necessário o desenvolvimento de projetos específicos para um local que trabalhem a diversidade do ser humano e invistam em mudança de comportamento.

A maioria concordou que a educação ambiental foi capaz de desenvolver a APA do Maracanã, representada por $85 \%$ dos respondentes, justificando que a educação favorecia o conhecimento maior em relação aos benefícios que uma área conservada traz para uma comunidade e de como desenvolvê-la sem agredir os recursos naturais.

Sendo assim, pôde-se afirmar que a EA contribuiu para o desenvolvimento da comunidade na medida em que tinha o ecoturismo como uma modalidade essencial para o desenvolvimento econômico e a conservação ambiental e a informação e conscientização para o desenvolvimento ético e uma equidade social.

\section{CONCLUSÃO}

Identificou-se que somente os esforços de poucos, como os dos responsáveis pelos projetos de educação ambiental da Secretaria Municipal de Turismo e de algumas escolas da comunidade, além de ações de alguns moradores, não estavam suprindo a rapidez com que os recursos naturais da APA estavam sendo devastados.

\footnotetext{
3 WELlS, M.; BRANDON, K. People and parks: linking protected area management with local communities.World Bank/World Wildlife Fund/USAID, Washington, D. C., U. S. A., 1992.
} 
Também se chegou à conclusão que as pessoas que contribuíam de fato para a conservação da APA eram as que participavam ou já haviam participado de cursos de educação ambiental, demonstrando assim, a capacidade desta na mudança de conduta e de atitudes diante do meio ambiente.

Sugeriu-se então, que houvesse uma cobrança maior da comunidade junto ao poder público para a realização inicial do plano de manejo da unidade para que fosse estabelecido o zoneamento da APA, bem como a determinação das atividades a serem desenvolvidas no interior da mesma. Além disso, implementar um amplo programa de educação ambiental que afetasse a todos para que fosse implementada uma consciência ecológica na comunidade, onde a mesma pudesse estar apta a cobrar ações de conservação do meio ambiente e conseqüentemente de melhoria de qualidade de vida. Além de se estabelecer uma competência para denunciar agressões antrópicas sobre a mesma.

Ainda, diante dos resultados obtidos nesse contexto, identificou-se a necessidade de surgirem novos estudos em relação ao assunto buscando melhor entender o descaso do poder público e de também delinear o perfil dos visitantes da APA não só na Festa da Juçara como também nas trilhas ecológicas. Outro aspecto a ser levantado seria o de obter a coleta da opinião desses em relação ao repasse de informações dos agentes ambientais no decorrer da trilha, se os mesmos conseguem propagar nos visitantes uma atitude mais consciente em relação ao meio ambiente, analisando desse modo a contribuição da educação ambiental para os visitantes.

Como a políticas públicas na APA não tiveram continuidade, assim como os projetos de educação ambiental, o que se vê em 2011 é uma degradação dos recursos naturais por parte da comunidade e do governo, ambos por permitirem ações de impacto como poluição dos rios e mangues. O que poderia ser uma fonte de recursos e uma opção para roteiros turísticos em São Luís está hoje esquecido e abandonado.

Com exceção do Parque da Juçara que a cada ano vem mantendo-se com dificuldades para a realização da tradicional festa gastronômica da região. 


\section{REFERÊNCIAS}

ANDRADE, S. A. de A. Considerações gerais sobre a problemática ambiental. In: LEITE, A. L. T. de A.; MININNI-MEDINA, N. (Coord.). Educação Ambiental: curso básico à distância: questões ambientais, conceitos, história, problemas e alternativas. 2 . ed. ampl. Brasília, DF: Ministério do Meio Ambiente, 2001. v. 3.

ARAÚJO, M. do S. São Luís, turismo e memória: uma década de experiências da gestão pública municipal. São Luís: Secretaria Municipal de Turismo, 2007.

BRASIL. Política Nacional de Meio Ambiente. Lei n. 9795/99. Disponível em: <http://www.planalto.gov.br/ccivil/Leis/L9795org.htm>. Acesso em: 28/01/2011.

CHAVES, J. R. de V. Projeto Maracanã - Do discurso à prática da sustentabilidade: estudo sobre as percepções dos agentes ambientais e os reflexos do desenvolvimento das ações no meio ambiente, no lazer e na qualidade de vida. Dissertação (Mestrado em Saúde e Ambiente) - Universidade Federal do Maranhão, São Luís, 2007.

COMISSÃO MUNDIAL DO MEIO AMBIENTE E DESENVOLVIMENTO. Nosso futuro comum. 2. ed. Rio de Janeiro: FGV, 1991.

DIAS, G. F. Educação ambiental: princípios e práticas. São Paulo: Gaia, 2004.

DIAS, R. Turismo sustentável e meio ambiente. São Paulo: Atlas, 2003.

GOOGLEMAPS. MAPA de São Luís, 2011. Disponível em: <www.googlemaps.com.br>. Acesso em: 30/01/2011.

IBGE. INSTITUTO BRASILEIRO DE GEOGRAFIA E ESTATÍSTICA. Disponível em: <http://www.ibge.gov.br>. Acesso em: 15/05/2011.

KINKER, S. Ecoturismo e conservação da natureza em parques nacionais. Campinas, SP: Papirus, 2002. - (Coleção Turismo).

MARGULIS, S., Meio ambiente: aspectos técnicos e econômicos. 2. ed. Brasília: IPEA, 1996.

MININNI-MEDINA, N. Documentos nacionais de educação ambiental. In: LEITE, A. L. T. de A.; MININNI-MEDINA, N. (Coord.). Educação ambiental: curso básico à distância: documentos e legislação de educação ambiental. 2. ed. ampl. Brasília, DF: Ministério do Meio Ambiente, 2001. v. 4.

MOLINA, S. E. Turismo e ecologia. Bauru, SP: EDUSC, 2001. - (Coleção Turismo). 
O QUE é o PNUMA? 2008. Disponível em: $<\mathrm{http}$ ://www.brasilpnuma.org.br/opnuma/oqueeopnuma.htm>. Acesso em: 20/09/2008.

OMT. Organização Mundial do Turismo. Guia de desenvolvimento do turismo sustentável. Porto Alegre: Brookman, 2003.

SANTILLI, J. Socioambientalismo e novos direitos. São Paulo: Peirópolis, 2005.

TRIPÉ do desenvolvimento sustentável, 2008. Disponível em: <http://a21 armamar.files.wordpress.com/2007/11/esquema2.gif>. Acesso em: 28/01/2011.

Recebido em: 04-07-2011.

Aprovado em: 04-08-2011. 